\title{
COORDENAÇÃO PEDAGÓGICA: ESPAÇO-TEMPO DE ORGANIZAÇÃO DO TRABALHO PEDAGÓGICO E DE FORMAÇÃO CONTINUADA
}

\author{
THIAGO GONÇALVES FERREIRA DO NASCIMENTO'
}

\begin{abstract}
${ }^{1}$ Professor da Educação Básica da Secretaria de Educação do Distrito Federal desde 2005, mestrando em educação pelo Programa de Pós-graduação em Educação da Faculdade de Educação da Universidade de Brasília (UnB), membro do Grupo de Estudos e Pesquisas Sobre Formação e Atuação de Professores/Pedagogos (GEPFAPe). thiago.tgfn@gmail.com
\end{abstract}

\section{RESUMO}

A presente pesquisa teve como escopo compreender as relações existentes entre coordenação pedagógica, formação continuada, projeto político-pedagógico e organização do trabalho pedagógico. Destarte, numa abordagem qualitativa, contou com a participação de 13 docentes dos anos iniciais da rede pública de ensino do DF, atuantes na Coordenação Regional de Ensino de Brazlândia; os dados encontrados foram analisados à luz dos construtos teóricos de Veiga (1996), Villas Boas (2002), Fullan e Hargreaves (2006), Silva (2007), Fernandes (2007) e Silva e Fernandes (2017). Para se contextualizar a institucionalização do espaço-tempo da coordenação pedagógica, foi realizada pesquisa bibliográfica para o levantamento dos principais marcos legais, a saber, a Lei 9.394/96 - que estabelece as diretrizes e bases da educação nacional, a Lei 11.738/2008 - que institui o piso salarial para os profissionais do magistério público da educação básica e, no âmbito do Distrito Federal, a Lei $5.105 / 2013$ - que institui o vigente plano de carreira do magistério público do DF. Para fomentar o debate, são utilizados também, como aporte teórico, os construtos de Freitas (1995), Ferreira (2010) e Fuentes e Ferreira (2017). Há que se destacar que a coordenação pedagógica é um espaço-tempo primordial para a formação continuada e para a organização do trabalho pedagógico.

Palavras-chave: Coordenação Pedagógica; Formação Continuada; Organização do Trabalho Pedagógico.

\section{PEDAGOGICAL COORDINATION: TIME-SPACE FOR ORGANIZING PEDAGOGICAL WORK AND CONTINUING TRAINING}

\begin{abstract}
This research aimed to understand the existing relationships between pedagogical coordination, continuing education, political-pedagogical project and organization of pedagogical work. Thus, in a qualitative approach, it counted with the participation of
\end{abstract}


13 teachers from the early years of the public school system in DF, working in the Regional Teaching Coordination of Brazlândia and the data found were analyzed in the light of the theoretical constructs of Veiga (1996), Villas Boas (2002), Fullan and Hargreaves (2006), Silva (2007), Fernandes (2007) and Silva and Fernandes (2017). In order to contextualize the institutionalization of the pedagogical coordination spacetime, a bibliographic research was carried out to survey the main legal frameworks, namely Law 9.394 / 96 - which establishes the guidelines and bases of national education, Law 11.738 / 2008 - which it establishes the salary floor for professionals in the public teaching of basic education and, within the scope of the Federal District, Law 5,105 / 2013 - which establishes the current career plan for the public teaching of the Federal District. To construct the debate, the constructs of Freitas (1995), Ferreira (2010) and Fuentes and Ferreira (2017) are also used as a theoretical contribution. It should be noted that pedagogical coordination is an essential space-time for continuing education and for organizing pedagogical work.

Keywords: Pedagogical Coordination; Continuing Education; Organization of Teaching Work.

\section{INTRODUÇÃO}

Tratar do tema educação é, via de regra, enveredar por um complexo debate, uma vez que, enquanto atividade fundamental intrinsecamente ligada à ontológica categoria trabalho, é o processo por meio do qual desde os primórdios da existência humana se reproduz, desenvolve e transforma-se a sociedade, garantindo-se às gerações mais novas o aprendizado da experiência acumulada pelos homens ao longo do tempo.

A escola, enquanto instituição social tida como lócus privilegiado de realização do processo educativo, possui uma função social de extrema relevância ao passo que se vê imersa num complexo emaranhado de interesses antagônicos provenientes de uma sociedade dividida em classes, regida sob a égide do capital.

À medida que os modos de produção na sociedade capitalista se complexificaram, as relações de produção modificaram-se, alterando a relação capitaltrabalho, o que impactou nas relações sociais e, por conseguinte, nos direcionamentos das instituições sociais. Outrossim, o debate acerca da formação docente e da realização do trabalho pedagógico passou a ganhar cada vez mais evidência e externar a relevância de atentar-se para os tempos e espaços que podem contribuir no processo de realização da ação educativa por meio do trabalho pedagógico, para que, conforme apregoa Silva (2007, p. 1), possa-se "construir a partir da educação um projeto que atenda aos anseios da sociedade, não prescindindo de transformá-la”. 
Dessa forma, emergiu o interesse em compreender de que maneira a coordenação pedagógica contribui ou pode vir a contribuir com a organização do trabalho pedagógico, bem como as relações existentes entre coordenação pedagógica, formação continuada e projeto político-pedagógico.

Tais análises consubstanciam-se como objetivos deste capítulo, e, para alcançálos, foi realizada pesquisa qualitativa com professores dos anos iniciais do ensino fundamental da rede pública de ensino do Distrito Federal atuantes na Coordenação Regional de Ensino de Brazlândia. Como instrumento para levantamento dos dados, utilizou-se um questionário com questões para caracterizar os participantes e questões abertas versando sobre a coordenação pedagógica e suas relações com o projeto político-pedagógico, a formação continuada e a organização do trabalho pedagógico. Ao todo, foram distribuídos 25 questionários tendo sido devolvidos respondidos 13 deles. Como aporte teórico, utilizam-se os construtos de Veiga (1996), Villas Boas (2002), Fullan e Hargreaves (2006), Silva (2007), Fernandes (2007) e Silva e Fernandes (2017).

\section{PERCURSO DE INSTITUCIONALIZAÇÃO DO ESPAÇO-TEMPO DA COORDENAÇÃO PEDAGÓGICA}

A Lei 9.394/96, que estabelece as atuais diretrizes e bases da educação nacional, em alguns de seus dispositivos, traz a previsão legal de períodos em que possa haver dedicação ao planejamento, à avaliação e ao desenvolvimento profissional (entendendose que, para atingir este último aspecto, é necessário que se vivencie processos de formação).

Art. 13. Os docentes incumbir-se-ão de:

[...]

V - ministrar os dias letivos e horas-aula estabelecidos, além de participar integralmente dos períodos dedicados ao planejamento, à avaliação e ao desenvolvimento profissional;

Art. 67. Os sistemas de ensino promoverão a valorização dos profissionais da educação, assegurando-lhes, inclusive nos termos dos estatutos e dos planos de carreira do magistério público:

[...]

V - período reservado a estudos, planejamento e avaliação, incluído na carga de trabalho; (BRASIL, 1996, on-line).

Ao trazer assentada como marco legal a existência desses períodos, a LDB reconhece a importância de haver tempos em que se possa planejar, premissa básica de 
qualquer ação intencional, uma das características primordiais do ato educativo, refletir e formar-se de modo a se atingir o desenvolvimento profissional. No entanto, não faz menção a quanto tempo se referem esses períodos nem em quais espaços eles se efetivarão.

Assim sendo, a Lei 11.738/2008, que institui o piso salarial para os profissionais do magistério público da educação básica, revelou-se ser uma tentativa de avanço no tocante a este aspecto. Ela traz um percentual a ser observado dentro da jornada de trabalho que não deve ser utilizado para interação com os educandos, a saber, 1/3, pois fixa em $2 / 3$ o limite máximo de tempo com tal interação: “Art. $2^{\circ}$ [...]§ $4^{\circ}$ Na composição da jornada de trabalho, observar-se-á o limite máximo de 2/3 (dois terços) da carga horária para o desempenho das atividades de interação com os educandos." (BRASIL, 2008, on-line).

A questão é que a norma legislativa parece ter se utilizado de uma lógica inversa, em que demarca, na prática, o tempo para relação direta entre professores e alunos, mas deixa uma lacuna em um não-dito quanto ao $1 / 3$ restante, abrindo assim margem às mais distintas interpretações e arguições segundo os interesses de quem as realiza. Se o principal intuito era que essa reserva temporal se destinasse ao cumprimento do que dispusera a LDB, isto não ficou claro, deixando brechas a contestações. Contestações que não tardaram a surgir e que retardaram em muito o pleno cumprimento da eficácia da norma. Tão logo passou a ter seus efeitos válidos, Ceará, Mato Grosso do Sul, Paraná, Santa Catarina e Rio Grande do Sul ajuizaram a Ação Declaratória de Inconstitucionalidade 4167 questionando a constitucionalidade da lei, em especial o Art. $2^{\circ}$, que versa sobre o valor do piso e a destinação temporal da jornada de trabalho.

No ano seguinte, 2009, o Conselho Nacional de Educação emitiu, por meio da Câmara de Educação Básica, o parecer n. 9/2009, indicando que o mínimo de 1/3 da jornada de trabalho deveria ser destinado a atividades extraclasse, e que tal prerrogativa mostrava-se consoante ao disposto no inciso V do art. 67 da Lei 9394/96.

Art. 67. Os sistemas de ensino promoverão a valorização dos profissionais da educação, assegurando-lhes, inclusive nos termos dos estatutos e dos planos de carreira do magistério público:

[...]

V - período reservado a estudos, planejamento e avaliação, incluído na carga de trabalho; (BRASIL, 1996). 
Todavia, como estava suspenso por força de liminar, o $\S 4^{\circ}$ do art. $2^{-}$da Lei 11.738/2008 não surtiu efeitos.

\begin{abstract}
Art. 2o O piso salarial profissional nacional para os profissionais do magistério público da educação básica será de $\mathrm{R} \$$ 950,00 (novecentos e cinqüenta reais) mensais, para a formação em nível médio, na modalidade Normal, prevista no art. 62 da Lei n ${ }^{\circ} 9.394$, de 20 de dezembro de 1996, que estabelece as diretrizes e bases da educação nacional.

[...]

§ 4ํNa composição da jornada de trabalho, observar-se-á o limite máximo de $2 / 3$ (dois terços) da carga horária para o desempenho das atividades de interação com os educandos. (BRASIL, 2008).
\end{abstract}

Somente em 2011, portanto três anos após a edição da referida norma, o Supremo Tribunal Federal (STF) julgou a constitucionalidade da reserva de 1/3 da jornada de trabalho para se dedicar a estudos, planejamento e avaliação; entretanto, após um empate de 5 a 5 e uma abstenção, a decisão do plenário definiu pela legalidade da reserva deste tempo para essas atribuições, ressaltando inclusive que o espaço das atividades extraclasse deveria também ser momento de formação continuada do professor no próprio local de trabalho. Entretanto, por não alcançar 6 votos, não logrou efeito vinculante nacionalmente, abrindo margem para novas contestações em nível estadual e, possivelmente, uma nova contestação frente ao próprio STF.

Por suas especificidades, o trabalho pedagógico precisa articular categorias que são inerentes a si e que são constituintes de seu próprio processo de realização. Segundo Freitas (2008, p. 95), essas categorias são os pares dialéticos objetivos gerais/avaliação da escola e conteúdo/forma geral do trabalho pedagógico da escola, que, por sua vez, modulam categorias mais específicas no interior do próprio trabalho pedagógico, sobretudo na sala de aula, tais como: objetivos/avaliação de ensino, conteúdos/métodos de ensino, etc.

Para que se torne possível tal articulação, é necessário que haja espaços em que se possa ter processos formativos, de planejamento e de construção coletiva de um projeto educativo que seja capaz de concretizar os aspectos teleológicos da ação educativa. Um desses espaços, segundo Silva (2007), é a coordenação pedagógica, a qual "constitui-se como espaço privilegiado para tais finalidades, em que pode-se construir, implementar, acompanhar e avaliar o projeto político-pedagógico e, em decorrência, transformar o trabalho educativo" (p.2). 
No âmbito do Distrito Federal, lócus em que se desenvolveu a pesquisa, o espaço-tempo da coordenação pedagógica passou por várias configurações. Conforme Fernandes (2007, p. 75), na década de 1960, a “coordenação pedagógica”, ou melhor, o horário complementar ficava a cargo dos orientadores de ensino (função atualmente exercida pelo coordenador pedagógico) e, na falta deste, do diretor escolar, e, segundo Rocha (1969, on-line), possuía a concepção de "assistência pedagógica e crescimento profissional pelo intercâmbio de experiências entre os professores". Os professores, contratados sob o regime da Consolidação das Leis Trabalhistas (CLT), possuíam carga horária de trabalho de 20 horas de regência e 04 horas de horário complementar. $\mathrm{Na}$ década de 1970, houve a possibilidade de ampliação da carga de trabalho de 20 para 40 horas em função de programas e projetos educacionais, como o Projeto ABC, por exemplo. Nessa época e também na década de 1980, em que houve a implantação do Ciclo Básico de Alfabetização, os professores distribuíam sua carga horária em 32 horas de regência (em duas turmas, no caso dos anos iniciais) e 08 horas de coordenação pedagógica, possibilitada pela existência do professor-dinamizador, que desenvolvia conteúdos de Educação Artística, Recreação e Jogos em torno das datas comemorativas - "o que, geralmente, não guardava vínculo com o trabalho desenvolvido em sala pelo professor regente" (FERNANDES, 2007, p. 80).

Neste momento histórico, o paradigma educacional que imperava era o da racionalidade técnica, que, pelas condições objetivas e materiais postas, direcionava o fazer pedagógico no mais das vezes para a realização de um trabalho alienado.

Nos anos de 1990, com o advento da proposta Escola Candanga, houve a ampliação da jornada diária de aula para os estudantes de 4 para 5 horas e a ampliação da jornada de trabalho dos professores, numa divisão que contemplava 25 horas de regência (numa única turma, no caso dos anos iniciais) e 15 horas de coordenação pedagógica (em turno contrário ao da regência), a ser conduzida pelo coordenador pedagógico. Segundo Fernandes (2007), nesse período, a coordenação pedagógica precisou ser ressignificada e, para que isso ocorresse, na perspectiva da proposta Escola Candanga (1996), foram assumidos como pressupostos: a) a Educação como um processo social e a escola espaço de constituição de práticas coletivas; b) a ação pedagógica como prática social transformadora e c) relação democrática comprometida com a cidadania, na escola. Assim, a coordenação pedagógica passou a ser concebida 
como um momento essencial de constituição da ação coletiva, de reflexão e troca de conhecimentos que contribuiriam para a construção de uma prática pedagógica eficaz e para a implantação de uma nova qualidade de ensino nas escolas públicas do Distrito Federal.

Atualmente, a coordenação pedagógica possui previsão assentada no dispositivo legal que institui o vigente plano de carreira do magistério público do DF, a Lei $5.105 / 2013$. Cumpre observar que, de maneira até "privilegiadamente" diferenciada embora não devesse parecer um privilégio, mas uma regra para todo o país -, o DF conta com a garantia legal de 33\% da carga horária destinada à coordenação pedagógica para aqueles que atuam 20 horas semanais e $37,5 \%$ para os que atuam no regime de 40 horas semanais. Uma conquista significativa para o trabalho docente, fruto de muita luta dos professores do Distrito Federal. Esse tempo, segundo a Lei 5.105/2013, deve ser relativo ao "conjunto de atividades destinadas à qualificação, à formação continuada e ao planejamento pedagógico que, desenvolvidas pelo docente, dão suporte à atividade de regência de classe" (DISTRITO FEDERAL, 2013, on-line).

Segundo as Diretrizes Pedagógicas para a Organização Escolar do $2^{\circ}$ Ciclo para as Aprendizagens: BIA e $2^{\circ}$ Bloco, a Coordenação Pedagógica é um dos cinco elementos constitutivos da Organização do Trabalho Pedagógico Escolar (DISTRITO FEDERAL, 2014a, p.20). Posição também elencada nas Diretrizes Pedagógicas para a Organização Escolar do $3^{\circ}$ Ciclo para as Aprendizagens, em se tratando dos anos finais do ensino fundamental, que ainda pondera que o seu fortalecimento é condição para garantir as aprendizagens (DISTRITO FEDERAL, 2014b, p. 23).

Assim sendo, os documentos norteadores da etapa do Ensino Fundamental da rede pública de ensino do Distrito Federal elencam a coordenação pedagógica como lócus privilegiado de organização do trabalho pedagógico escolar, em que se possibilita, entre outras coisas, "a formação continuada docente, o planejamento e avaliação dos trabalhos pedagógicos, bem como o atendimento às dificuldades específicas de aprendizagem dos estudantes" (DISTRITO FEDERAL, 2014b, p. 31).

\section{COORDENAÇÃO PEDAGÓGICA: ESPAÇO-TEMPO ORGANIZADOR DE UM TRABALHO PEDAGÓGICO COLETIVO, COLABORATIVO}


Segundo Silva e Fernandes (2017), a discussão sobre a organização do trabalho pedagógico da escola parte de dois pressupostos: de que o trabalho pedagógico requer a instituição da cultura da colaboração, tendo a participação como premissa, isso porque não haveria como concebê-lo numa perspectiva formativa e reflexiva de forma individual e solitária; e, de que a organização do trabalho pedagógico da escola como um todo, no espaço e tempo da coordenação pedagógica, impacta o trabalho pedagógico realizado em sala de aula pelos professores e estudantes, evidenciando uma relação indissociável entre ambos (p. 1).

Questionados sobre o significado da coordenação pedagógica e de que maneira ela contribui ou pode vir a contribuir para a realização de um trabalho pedagógico colaborativo ou coletivo, os docentes, praticamente unanimemente, ressaltaram a importância deste espaço-tempo como primordial para a realização de um trabalho coletivo, embora poucos tenham indicado o caráter colaborativo, como ilustram as falas a seguir:

"Espaço de construção coletiva e reelaboração do cotidiano escolar". (Professora A)

"Momento de planejamento das atividades a serem realizadas na instituição, tanto de forma individual quanto coletiva". (Professora B)

"O momento em que individualmente ou em grupo os professores têm de discutir sua atuação em sala, programar suas atividades e se preparar para o dia a dia na $\mathrm{UE}^{1 "}$. (Professora $\mathrm{C}$ )

"Momento onde todos participam da elaboração das atividades a serem desenvolvidas, dando suas contribuições tais como experiência, atividades, etc". (Professor D)

Todos os sujeitos da pesquisa indicaram que há a realização da coordenação pedagógica nas unidades escolares em que atuam, 1 (um) dos respondentes indicou que a realização dela é coletiva e 12 (doze) que se dá de forma individual e coletiva. Indagados sobre a dinâmica da coordenação pedagógica, alguns afirmaram que planejam atividades individuais em determinados momentos e se reúnem com seus pares por ano/disciplina noutros, outros disseram se reunirem para planejamento coletivo e ainda houve os que responderam ser um espaço para informes diários, embora também comporte estudos.

"A coordenação ocorre juntamente com os professores do mesmo ano no qual estou, selecionamos os conteúdos que vamos trabalhar na semana e planejamos as atividades juntos". (Professora E)

\footnotetext{
${ }^{1}$ Unidade de Ensino.
} 


\begin{abstract}
"Em dois dias ocorrem as coordenações por disciplina e toda quarta-feira ocorre a coordenação coletiva envolvendo todo o colegiado para definição de estratégia ou estudos direcionados. Há ainda dois dias destinados à coordenação individualizada que pode ocorrer fora da escola”. (Professor F)

"Um dia na semana o espaço da coordenação é destinado ao planejamento das ações pedagógicas semanais e atendimento às demandas coletivas. Um dia é destinado à coordenação coletiva, espaço de formação continuada, feita pela própria escola ou respondendo a demandas regionais ou da $\mathrm{SEDF}^{2}$. Um dia destinado à formação do professor, conforme plano de carreira do magistério, e atendimento individualizado aos alunos". (Professora G)

“Estudos e informes diários”. (Professora H)
\end{abstract}

Caso objetive-se formar uma cultura colaborativa de organização do trabalho pedagógico, mister se faz haver dinâmicas de interações e processos de fato colaborativos. Fullan e Hargreaves (2006) evidenciam que o trabalho conjunto é a forma mais sólida de colaboração (por exemplo, ensino em equipe, planejamento, observação, pesquisa, treinamento entre colegas, orientação, etc.). Segundo os autores, o trabalho conjunto, colaborativo, implica e gera maior interdependência, responsabilidades compartilhadas, compromisso coletivo e progresso, e uma maior disposição para participar nas difíceis tarefas de revisão e crítica. É a modalidade de trabalho em equipe e cultura escolar mais propícia à melhoria significativa, tanto da escola como um todo quanto da aprendizagem dos alunos.

É esta a perspectiva que se observa em falas como:

"O grupo se reúne, existe uma pauta que é feita a partir das necessidades de
cronograma, calendário e pontos pungentes na dinâmica escolar, estes pontos
são debatidos e construídas as estratégias para práxis pedagógica. Esse
momento também é usado para formação continuada dentro e fora da unidade
escolar, além de ocasiões de troca com as escolas parceiras da escola parque,
chamadas de coletivas compartilhadas". (Professora A)

"Momento onde todos participam da elaboração das atividades a serem desenvolvidas, dando suas contribuições tais como experiência, atividades etc". (Professora B)

"Estimulando a troca entre todos, respeitando os espaços e a individualidade na busca de melhores experiências para todos, alunos e a própria equipe pedagógica". (Professora J)

Entretanto, os autores categorizam três formas de trabalho coletivo que inspiram cautela, são elas: a balcanização, a cooperação fácil e o trabalho em equipe artificial (FULLAN e HARGREAVES, 2006).

\footnotetext{
${ }^{2}$ Secretaria de Estado de Educação do Distrito Federal.
} 
Posições como: a coordenação ocorre juntamente com os professores do mesmo ano no qual estou, selecionamos os conteúdos que vamos trabalhar na semana e planejamos as atividades juntos (Professora I) indicam a necessidade de se ter atenção para não se restringir a interação somente com os pares de mesmo ano/série de atuação, deixando em segundo plano o coletivo como um todo, como numa interação balcanizada.

A balcanização se caracteriza pela formação de grupos separados, cada um em seu balcão de afinidades, que, num viés mais extremista, pode culminar na falta de interação e comunicação intergrupos. É preciso se reconhecer a importância do contexto coletivo da escola como um todo, bem como a relevância da cooperação colaborativa entre grupos distintos (FULLAN e HARGREAVES, 2006).

A cooperação fácil tem como característica a "troca de estratégias e o compartilhamento de materiais de natureza mais imediata, específica e técnica". Se concentra no curto prazo e exclui os problemas do planejamento de longo prazo. "Não contempla os princípios de uma prática reflexiva sistemática" (FULLAN e HARGREAVES, 2006, p. 94). Falas como: momento de elaboração de aula, escolha dos melhores conteúdos e métodos para passar para os alunos (Professora E) exemplificam este tipo de trabalho e demonstram a necessidade de se pensar num trabalho coletivo que supere os imediatismos.

Já o trabalho em equipe artificial, caracteriza-se por "uma série de procedimentos formais, específicos e burocráticos que privilegiam o planejamento conjunto entre professores, a consulta entre eles e outras formas de colaboração" (FULLAN e HARGREAVES, 2006, p. 94). É possível identificar isso em falas como: "São impostos temas e atividades com o objetivo de melhorar e aperfeiçoar o ensino na escola; estudos e informes diários" (Professora K).

Segundo os autores, este tipo de trabalho pode operar em duas direções: da forma mais negativa, pode se tornar um substituto administrativo do que deveria de fato ser um trabalho pedagógico colaborativo e, da forma mais positiva, pode representar uma fase preliminar propícia à construção de relações cooperativas (FULLAN e HARGREAVES, 2006).

É primordial se utilizar o espaço-tempo da coordenação pedagógica para se realizar interações crítico-reflexivas entre os pares e intergrupos para se ter, de fato, um 
trabalho pedagógico coletivo, mas, que, para além deste aspecto, ele se torne verdadeiramente cooperativo e colaborativo.

\section{COORDENAÇÃO PEDAGÓGICA COMO ESPAÇO-TEMPO DE FORMAÇÃO CONTINUADA}

Na sociedade contemporânea, as mudanças técnico-científicas operadas no setor produtivo e a busca por melhores níveis de qualidade de ensino colocaram novas exigências para a escola pública e para os profissionais que nela atuam. O impacto da globalização, associado à revolução tecnológica, alterou os padrões de conhecimento. Nesse processo, passaram a ter destaque as preocupações com a formação do professor para lidar com a complexidade das novas demandas que envolvem o trabalho docente (SILVA, 2007).

Nesse contexto, realça-se ainda mais a importância da formação continuada e da coordenação pedagógica enquanto lócus propiciador de sua realização. Sendo ambas pilares da organização do trabalho pedagógico, a formação continuada realizada no espaço-tempo da coordenação pedagógica possui o enfoque de formação centrada na escola, que, segundo Silva (2007), traz como pressuposto ser o professor quem melhor conhece a sua realidade com as problemáticas e questões que emergem no seu contexto de trabalho, o que corrobora a afirmação de Nóvoa (2001, p. 12) de que "é no espaço concreto de cada escola, em torno de problemas pedagógicos ou educativos reais de cada escola, que se desenvolve a verdadeira formação".

É interessante observar que, quando indagados sobre o que representava a coordenação pedagógica, muitos já indicaram a sua destinação para a formação continuada. Quando questionados sobre a realização ou não de formação continuada na coordenação pedagógica, onze dos treze respondentes indicaram que sim, há formação continuada; no entanto, dois revelaram não haver formação continuada nas escolas em que atuam, o que faz ligar um alerta, uma vez que, em não havendo essa formação, aumenta-se a probabilidade se de perpetuar práticas reiterativas, reprodutivistas e se realizar um trabalho alienado. 
Acerca da periodicidade com que ocorrem, seis indicaram que há formação a cada quinze dias, três indicaram uma vez ao mês e quatro relataram ser as "necessidades" o propulsor de sua ocorrência.

Descrevendo a dinâmica de realização dessa formação continuada, alguns a retrataram das seguintes maneiras:

\footnotetext{
"Nas coletivas, com estudo dos temas propostos pela $\mathrm{UE}^{3}, \mathrm{CRE}^{4}, \mathrm{SEDF}^{5}$. Nas coordenações individuais/coletivas, desenvolvendo dinâmicas para os professores de acordo com solicitação". (Professora A)

"Estudos sobre temas de atualização na educação". (Professor B)

"Estudos sistematizados a respeito de temas pré-determinados ou emergentes, que podem ser explanados pelo coordenador pedagógico ou outra pessoa mais qualificada em relação ao tema abordado". (Professor H)
}

Cumpre destacar aqui a relação com a contemporaneidade, as demandas emergentes do grupo e contexto e a destinação do coordenador como condutor deste momento, entretanto, não como único responsável.

\section{O PROJETO POLÍTICO-PEDAGÓGICO E A COORDENAÇÃo PEDAGÓGICA}

Segundo Veiga (1996, p. 20), o projeto político-pedagógico "não deve limitar-se aos conteúdos curriculares, mas se estender à discussão da escola como um todo e suas relações com a sociedade". Silva (2007) entende ser ele o eixo norteador do trabalho da escola e da coordenação pedagógica - espaço de formação continuada do professor, o qual deve procurar mostrar a indissociabilidade entre esses elementos na transformação do trabalho escolar, bem como da unicidade teoria-prática no trabalho pedagógico. A este viés, as autoras denominam de caráter emancipador do $\mathrm{PPP}^{6}$.

Conforme Silva e Fernandes (2017), o PPP é o documento que organiza e sistematiza o trabalho da escola. Por meio dele, todo o planejamento de atividades é sistematizado, o que propicia o acompanhamento e, inclusive, a sua avaliação. É também ele o instrumento que sinaliza novos caminhos e possibilidades para que o professor invista em sua formação nos espaços da própria escola, dinamizando-os e (re)

\footnotetext{
${ }^{3}$ Unidade de Ensino.

${ }^{4}$ Coordenação Regional de Ensino.

${ }^{5}$ Secretaria de Estado de Educação do Distrito Federal.

${ }^{6}$ Projeto político-pedagógico.
} 
significando-os na coordenação pedagógica. Dessa forma, segundo Silva (2007, p. 9), "reforça-se a relação de dialeticidade entre o projeto da escola e a coordenação pedagógica".

Quando questionados se a realização da coordenação pedagógica está inscrita no projeto político-pedagógico, dois dos respondentes disseram não haver menção a sua realização no PPP, o que é preocupante, pois é o documento basilar do trabalho pedagógico da escola. Quatro respondentes alegaram desconhecer se está ou não inscrita, fato que é ainda mais preocupante, uma vez que, sendo o PPP o documento norteador do trabalho pedagógico, tal desconhecimento revela não se ter ciência do teor dos princípios que organizam o trabalho que se desenvolve na instituição escolar. No entanto, sete afirmaram estar ela sim inscrita no PPP, em alguns casos da seguinte forma:

"É um espaço para a organização das atividades escolares e para a formação continuada dos profissionais de educação". (Professora L)

"Como espaço de formação, fruto de luta do magistério público, cujo pleno funcionamento favorece a organização da escola". (Professora M)

O que é um fator bastante positivo, uma vez que assenta explicitamente a destinação e a importância deste espaço-tempo.

\section{COORDENADOR PEDAGÓGICO: MERO BUROCRATA, UM TAREFEIRO OU O ARTICULADOR DO TRABALHO PEDAGÓGICO?}

Talvez seja este o ator educacional que mais careça de definição quanto a sua função e identidade profissional. Segundo Fernandes, de acordo com sua atuação, o coordenador pedagógico pode ser caracterizado como: a) coordenador burocrático contribui apenas com atividades burocráticas da função (fichas, relatórios, agendas); b) tarefeiro - voltado apenas para confecção de materiais; e c) coordenador responsável pelas aprendizagens de todos os estudantes. Este último procura dar ênfase a todas as dimensões da ação coordenadora que envolve o administrativo, o político, o pedagógico, entre outras, caracterizando-o como articulador do trabalho pedagógico coletivo (2007, p. 95). De acordo com a autora, o papel do coordenador pedagógico da educação básica seria o de articular o trabalho pedagógico, buscando a inovação por meio de ações instituintes, com ênfase na organização do trabalho pedagógico coletivo, 
nos processos de ensino, aprendizagem e avaliação. Nessa perspectiva, "o coordenador reuniria condições favoráveis à constituição do trabalho pedagógico, articulando os projetos a serem desenvolvidos no contexto escolar" (FERNANDES, 2010, p. 35).

Perguntados sobre a existência de coordenadores pedagógicos e se haveria divisão de funções entre eles, caso houvesse mais de um, todos afirmaram contar com coordenador pedagógico nas escolas em que atuam. Dois professores disseram contar com um coordenador na instituição escolar em que atuam, quatro afirmaram contar com dois coordenadores, três disseram haver três em suas unidades escolares e quatro afirmaram contar com quatro coordenadores em suas escolas, cada um com suas atribuições bem definidas quanto ao grupo a que auxiliam, embora se afirme que não há engessamento quanto às divisões, como exemplificam as falas a seguir:

“Sim. Pedagógico e educação integral”. (Professor H)

"Um cuida da Educação Infantil, $1^{\circ}$ e $2^{\circ}$ anos e o outro cuida dos $3^{\circ}, 4^{\circ}$ e $5^{\circ}$ anos. Auxilia também a todos que buscam, dando suporte geral". (Professor M)

"Eles dividiram em educação infantil e os outros anos. Ajudam a planejar os eventos e conteúdos principalmente em dias temáticos".

“A divisão é feita periodicamente dependendo das atividades, não há "engessamento" das funções". (Professor B)

"Um dos coordenadores é responsável por coordenar as turmas de anos iniciais. O segundo fica responsável pelas turmas de anos finais. O terceiro realiza um trabalho de conciliar as duas etapas de ensino e auxilia nas demandas pedagógicas da instituição no geral”. (Professora F)

"Na EPNBraz" foi desenvolvida uma maneira de trabalho que é orgânica, ou seja, as demandas são debatidas entre a equipe gestora e a pedagógica e divididas as tarefas conforme as afinidades e habilidades. Muitas vezes o trabalho dos coordenadores fica muito comprometido pela necessidade constante de substituição de professores". (Professor L)

Embora reconheçam a importância deste profissional e sua função, é interessante observar, na última fala, uma das múltiplas determinações que influenciam o trabalho do coordenador: a necessidade constante de substituição de professores, o que dificulta sua atuação como condutor do processo de formação continuada na escola, bem como de articulador dos processos de organização do trabalho pedagógico.

\section{CONSIDERAÇÕES FINAIS}

\footnotetext{
${ }^{7}$ Escola Parque da Natureza de Brazlândia.
} 
Para se alcançar um trabalho pedagógico que enseje transformar a realidade escolar, e, por conseguinte, social, é preciso ter-se em mente filosófica, gnosiológica, ontológica e epistemologicamente quais as concepções que se tem de homem, mundo, educação e sociedade, para que, conscientemente, saiba-se "que tipo de cidadão se pretende formar, para que sociedade e com que modelo de educação" (SILVA, 2007, p. 2).

Assim como tudo o mais que se relaciona à educação, nem o PPP enquanto instrumento, nem a formação continuada enquanto processo de formação, nem tampouco a coordenação pedagógica enquanto espaço-tempo são neutros, todos são carregados de crenças, valores e carga político-ideológica. Estar consciente disso é de extrema relevância.

Como se pôde observar, é inegável a importância da coordenação pedagógica bem como de sua previsão e inscrição no projeto político-pedagógico. Como muito bem evidencia Silva (2007), coordenação pedagógica, formação continuada e projeto político-pedagógico formam um "tripé pedagógico" cujas relações são de fundamental relevância para que se caminhe na direção da realização de um trabalho pedagógico coletivo e, mais que isso, colaborativo.

Em que pese ainda haver desafios a serem superados: como o cumprimento integral do tempo destinado à coordenação pedagógica, a definição clara das atribuições do coordenador pedagógico e o reconhecimento da relevância de sua função, a superação do errôneo entendimento de redução do PPP a mero documento burocráticoadministrativo, entre outros, a coordenação pedagógica é sim um importante espaçotempo de organização do trabalho pedagógico e de formação continuada, e, por meio dela, na articulação do "tripé pedagógico", pode-se caminhar na direção da práxis e de um trabalho pedagógico que prime por uma educação crítica, reflexiva e emancipadora, tendo em seu bojo o coordenador pedagógico como profissional da educação ressignificado e imbuído de autonomia para conduzir os processos inerentes à própria coordenação pedagógica e à organização do trabalho pedagógico.

\section{REFERÊNCIAS}


BRASIL. Ministério da Educação e Cultura. LDB - Lei no 9394/96, de 20 de dezembro de 1996. Estabelece as diretrizes e bases da educação nacional. Brasília: MEC, 1996.

BRASIL. Lei $\mathbf{n}^{\mathbf{0}}$ 11.738, de 16 de julho de 2008. Regulamenta a alínea "e" do inciso III do caput do art. 60 do Ato das Disposições Constitucionais Transitórias, para instituir o piso salarial profissional nacional para os profissionais do magistério público da educação básica. Disponível em: <http://www.planalto.gov.br/ccivil_03/_Ato20072010/2008/Lei/L11738.htm >. Acesso em: 20 de novembro de 2018.

DISTRITO FEDERAL. Secretaria de Estado de Educação. Diretrizes Pedagógicas para Organização Escolar do $2^{\circ}$ Ciclo para as Aprendizagens: BIA e $2^{\circ}$ Bloco. Distrito Federal: Secretaria de Estado de Educação, 2014a.

DISTRITO FEDERAL. Secretaria de Estado de Educação. Diretrizes Pedagógicas para Organização Escolar do $3^{\circ}$ Ciclo para as Aprendizagens. Distrito Federal: Secretaria de Estado de Educação, 2014b.

DISTRITO FEDERAL. Lei $\mathbf{n}^{\mathbf{0}}$ 5.105, de 03 de maio de 2013. Reestrutura a carreira Magistério Público do Distrito Federal e dá outras providências. Disponível em: <http://www.tc.df.gov.br/sinj/Norma/74206/Lei_5105_03_05_2013.html>.Acesso em: 01 de outubro de 2018.

FERREIRA, L. S. Trabalho pedagógico. In: OLIVEIRA, Dalila Andrade. et al. Dicionário trabalho, profissão e condição docente. Belo Horizonte: Faculdade de Educação UFMG, 2010.

FERNANDES, Rosana César de Arruda. Educação continuada, trabalho docente e coordenação pedagógica: uma teia tecida por professoras e 44 coordenadoras. Dissertação de Mestrado, Brasília, UnB, 2007.

FERNANDES, R.C.de A. Educação continuada de professores no espaço e tempos da coordenação pedagógica: avanços e tensões. In: VEIGA, I.P.A (org.). A escola mudou. Que mude a formação de professores!. Campinas, SP: Papirus, 2010.

FUENTES, R. C.; FERREIRA, L. S. Trabalho pedagógico: dimensões e possibilidade de práxis pedagógica. Perspectiva, Florianópolis, v. 35, n. 3, p. 722-7337, jul/set. 2017.

FULLAN.M; HARGREAVES A. Escuelas totales. In: FULLAN.M; HARGREAVES A. La escuela que queremos: los objetivos por los cuales vale a pena luchar. Buenos Aires: Amorrortu, 2006.

FREITAS, L. C. de. Crítica da organização do trabalho pedagógico e da didática. Campinas, SP: Papirus, 1995.

MINAYO, Maria Cecília de Souza. O desafio da pesquisa social. In: Pesquisa Social: teoria, método e criatividade. Vozes: Petrópolis, 2009.

NÓVOA, Antônio. Professor se forma na escola. Revista Nova Escola. São Paulo, nº 142, pp. 
18-20, maio, 2001.

ROCHA, A.B. da S. Ensino primário no Distrito Federal. Prefeitura do Distrito Federal. Secretaria de Educação. Coordenação de Educação Primária. Brasília, 1969.

SAVIANI, D. Trabalho e educação: fundamentos ontológicos e históricos. Revista Brasileira de Educação, Rio de Janeiro, v.12, n.34, p. 152-180, jan./abr. 2007.

SILVA, E.F.da. Coordenação pedagógica como espaço de organização do trabalho escolar: o que temos e o que queremos. In: VEIGA, I.P.A. (org.). Quem sabe faz a hora de construir o projeto político-pedagógico. Campinas, SP: Papirus, 2007.

SILVA, E.F.da; FERNANDES, R.C.A. Coordenação pedagógica: espaço e tempo de organização do trabalho pedagógico coletivo. In: VILLAS BOAS, B. (Org.). Avaliação: interações com o trabalho pedagógico. Campinas, SP: Papirus, 2017.

TORRES, R.S. Reuniões pedagógicas: espaço de encontro entre coordenadores e professores ou exigência burocrática? In: ALMEIDA, L.R.; PLACCO, V.M.N.de.S. (orgs.). $O$ coordenador pedagógico e o espaço da mudança. Edições Loyola, São Paulo, 2005.

VEIGA, I. P. A. (org.). Projeto político-pedagógico da Escola: uma construção possível. São Paulo: Papirus, 1996.

Inovações e projeto político-pedagógico: uma relação regulatória ou emancipatória? Cadernos CEDES, Campinas, v. 23, n. 61, p. 267-281, dez. 2003. 